\section{Briginal Slrticleg.}

\section{FORCIBLE CORRECTION IN LATERAL CURVATURE OF THE SPINE.'}

\section{Fourth Paper.}

BY ROBERT w, LOVETT, M.D., BOsTON.

THE problem to be met in the treatment of severe lateral curvature with fixed bony changes is a perfectly definite one. A clear understanding of the obstacles to be met and of the means at our disposal for meeting them is essential to successful treatment.

The spinal column having curved to one side has in the course of years become fixed in the deformed position. In addition to the side curve, a rotation or twist in the length of the column has occurred at the seat of the main and compensatory lateral curves. As the result of the maintenance of the vicious position over a long period of time, covering part of the period of growth, changes in bones, muscles, ligaments and intervertebral dises have occurred. The individual vertebræ have become compressed on one side and twisted by the rotation. The ligaments and muscles have become adaptively shortened on one side and stretched on the other and the intervertebral dises to a greater or less extent have become compressed on one side. The region of the vertebral column involved by the curve has lost its normal mobility and is partly or wholly stiff. There are secondary changes in the thorax and its contained organs but these are secondary also in importance.

It is obvious that in the upright position gravity works to increase the deformity by exerting pressure upon the concavity of the curves already atrophied by an abnormal weightbearing. Of the twenty-four hours in each day only some eight or ten at most are spent in recumbency. During the remaining fourteen or sixteen hours the vertical position is assumed and gravity is at work.

In formulating the relative value of the treatments proposed for the rectification of these severe structural changes in scoliosis it may not be unfair to consider the question on general grounds by comparing the condition, so far as the resultant deformity is concerned, to the common condition known as knock-knee. The bodies of the vertebra in the curved part of the spine have become affected in their growth so that they are smaller on the side of the concavity of the curve and have become wedgeshaped and the planes of their articulation with each other have become oblique to the horizon; that is, a condition mechanically to be compared to knock-knee exists between each two of the deformed vertebra.

It may be permissible to consider for a moment the means of correction at our disposal in knockknee to see what analogous methods may be useful in correcting an analogous mechanical condition in the spine.

1 Rend before the Boston Society for Medical Improvement, Dec. 21, 1903.
The means to be used in knock-knee are: (1) Massage, gymnastics and manual manipulation; (2) braces; (3) prolonged recumbency in a corrected position; (4) operation.

(1) Gymnastics, etc. If one took a girl of twelve with bony deformity sufficient to cause knock-knee and for an hour daily massaged, manipulated and exercised the legs one would expect but slight if any improvement. Even a treatment extending over several hours a day with the use of apparatus to localize and make more effective the exercises would hardly seem likely to prove efficient in the long run.

Gymnastics. The purely gymnastic treatment of severe structural scoliosis is to-day being largely pursued by two classes of persons. First by irresponsible masseurs and medical gymnasts who hold as a tradition that gymnastic exercises are curative or at least helpful in scoliosis, and, second, by competent surgeons who do not believe in corsets or supports. ${ }^{2}$ The former class serves only to bring the legitimate use of gymnastics for scoliosis into disrepute; the latter class use the gymnastics understandingly and on the whole take a pessimistic view of the results to oe obtained in severe scoliosis. The exercises of course are helpful so far as they go. They improve the muscular condition and by the development of the muscles of the back and sides they ooscure the curve of the spinous processes and equalize the contours of the body. Occasionally such gymnastics produce marked improvement in the patient's attitude. ${ }^{3}$

But to expect free muscular exercises to straighten, to any extent, curves caused by deformity of the vertebral bodies seems unreasonable.

Gymnastic treatment after forcible correction and in connection with effective support is, however, of the greatest value and may well be reckoned one of the essentials of successful treatment. ${ }^{4}$

Intermittent force and gymnastics. The use of intermittent corrective force in the treatment of the severer forms of lateral curvature remains to be spoken of. In connection with the use of gymnastics the combination forms to-day probably the most common treatment in use here and in Europe in the hands of competent specialists.

There are two aims of treatment to be kept in mind in this as in every form of treatment. The spine must be made more flexible and muscles must be developed to hold the improved position made possible by this increased flexibility. The treatment may be therefore divided into two heads: (1) Flexibility; (2) correction.

Flexibility is obtained by hanging and head suspension, active bendings and passive stretchings to one side; by the application of side force during suspension by the appliances of Hoffa, ${ }^{6}$ Weigel, ${ }^{6}$ Wullstein ${ }^{7}$ and Schede, ${ }^{8}$ and by the appliances of Schulthess. ${ }^{9}$ All these measures strive by their daily use to loosen up 
muscles and ligaments to enable the patient to assume a more correct position. They are of course useless without supporting and corrective muscular development, for flexibility gained without means of retaining it does more harm than good.

The correction or other part of the treatment is to be obtained by general and special muscular exercises, including the raising of heavy weirhts, etc. But free standing exercises are with difficulty accurately localized where they are needed and compensatory curves are likely to be increased.

The best development of such corrective work is to be found in the forms of apparatus devised by Schulthess, where resistive and active exercises are given in appliances which accurately localize the movement and control and regulate its force. They are described in detail by him.

(2) Braces and corsets. It is pretty gencrally admitted that the corrective effect of braces in straightening the curves in severe scoliosis is a very slight one. For the most part they are now used for this purpose by instrument makers who sell appliances which are largely worthless and by physicians unfamiliar with the problem of treatment who refer their patients to the instrument shops.

'To compare the condition again with knockknee one would expect but slow gain from the use of praces in a case of knock-knee in a child twelve years old. Yet here the femur and tibia furnish excellent levers for the use of corrective force and the force can be applied directly to the inner surface of the knee.

In severe scoliosis no such direct application of force is possible, as side pressure must be transmitted through the ribs and on account of the mobility of the column a long or accurate leverage is impossible as far as corrective force is concernerl.

Braces and corsets are, however, of the greatest use in maintaining the correction obtained by the use of force or by other means. The matter of their best form and construction is discussed at length in other places and many admirable forms exist. ${ }^{10}$

(3) Prolonged recumbency in the treatment of scoliosis is the relic of a bygone tradition and need not be discussed, being rarely advocated at present.

(4) Operation. The question of the operative relief of scoliosis is still subjudice. An operation was proposed by Volkmann in 1889, consisting of resection of the ribs on the convex side of the curve, and this operation was also performed by Hoffa ${ }^{11}$ with fair result. A similar operation was thought out by N. M. Shaffer of New York about fifteen years ago and spoken of to the writer at that time but never put on record, as the general surgeons to whom it was referred refused to sanction it. ${ }^{12}$

The latest and nest operative correction has been obtained by Hoke ${ }^{13}$ of Atlanta, Ga., who resected the ribs on the convex side of a girl of nineteen and lengthened those of the concave side in a severe dorsal curve. By the application of a corrective jacket great improvement was obtained.

These forms of treatment excepting the operative are not, however, new and have been tested by years of use, and the best comment on their value is to be found in the divided opinion of writers as to which is the best, and in the frequent expressions from competent persons of skepticism as to any great improvement to be expected in severe scoliosis under any therapeutic measures. ${ }^{14}$

It remains, therefore, to look the ground over once more to see if in the application of gencral surgical principles there is not some more rapid, rational and effective way of attacking the deformity than the methods described.

Of factors making for spontaneous improvement there are none so soon as a ccrtain stage of the deformity is reached. Of conditions to be utilized for the improvement there are two; one, of great significance, was elucidated by the experiments of Wullstein. ${ }^{15}$ Some young dogs were kept for months with the spines laterally flexed by means of bandages and springs. At the end of this time true lateral curvature with marked bony deformity of the type described above was present. It would secm fair to state from this that growth in a distorted position of the spine tended to produce deformity of the vertebra at the points of greatest pressure and that Wullstein's experiment needed only to be reversed to produce improvement in the severer cases of curvature in children still growing.

The second consideration bearing on the treatment is to be found in certain procedures in the manipulation for club foot, in which by forcible manipulation with the hands ${ }^{16}$ or a lever ${ }^{17}$ a distorted foot with abnormally shaped and improperly developed bones is made by a few minutes' forcible stretching to assume an approximately correct position. If it is held long cnough in the improved position, diminution of the deformity is secured. Two conclusions from the above-mentioned facts seem to me to bear upon the question under discussion: (1) Forcible manipulation can immediately stretch muscles and ligaments where the bones are avowedly deformed and seriously misshapen and can secure a temporary change in bony relations; (2) abnormal pressure from abnormal position during the period of growth will modify the shape of bones and stretch muscles and ligaments.

To put it still more simply the best chance of improvement in cases of severe scoliosis would seem to be (1) to use severe force to secure an improved and if possible an overcorrected position temporarily; (2) to retain as much as possible of the position thus secured during some part of the growing period. It is perfectly obvious that for this purpose a high degree of force will be necessary, especially in the case of adolescents. This force must be accurately localized during its application and the retention apparatus must be accurate and capable also of exerting retentive force of rather high degree. 


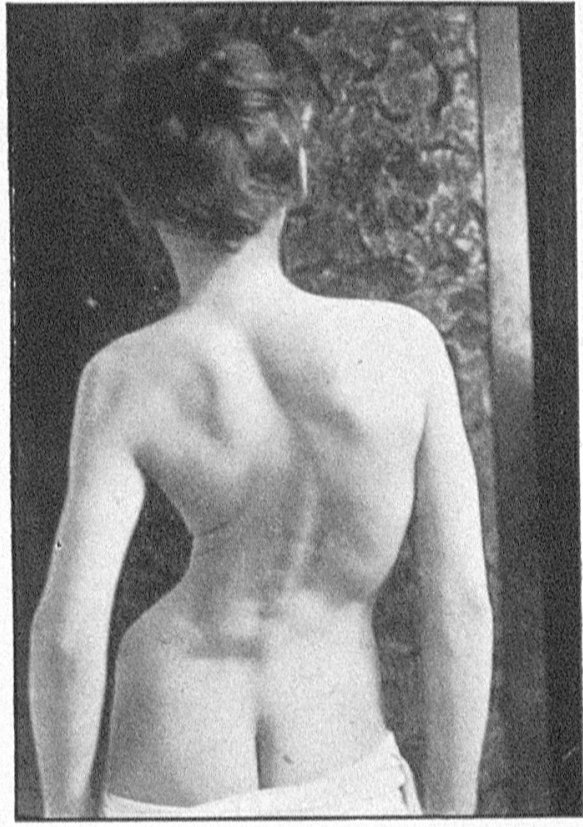

(ASt: 1 .
A 112, , 1300. 13 yeara olil. Brate 'lreatment.

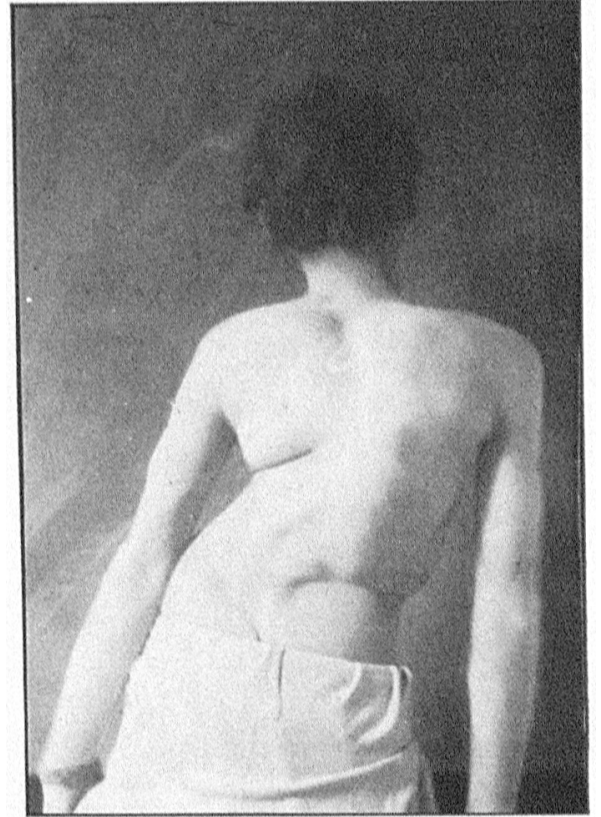

CAs: 1 .

Ja11., 19313 Hate. Trentment

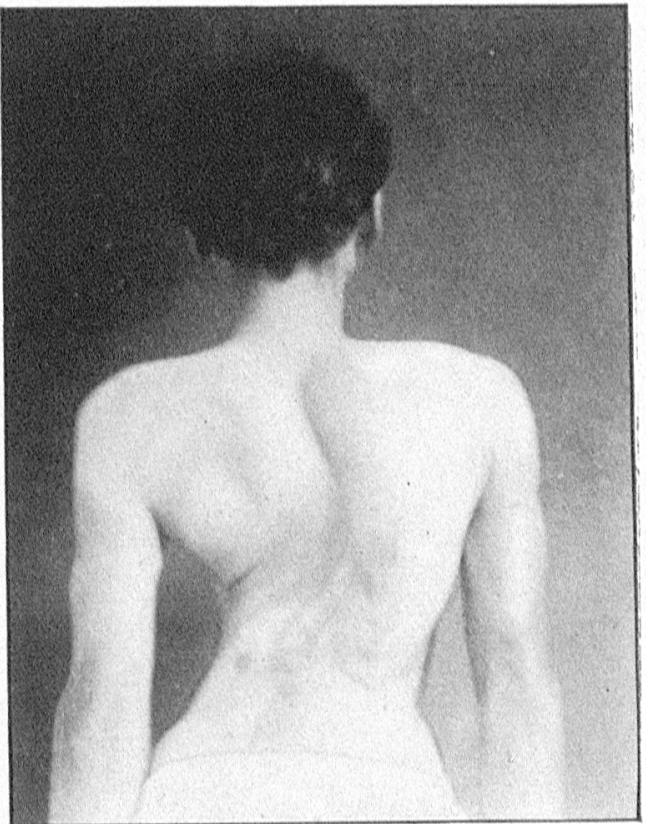

('A-1: 1. OA., 1H:

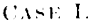
Fi.1., 1:11:3

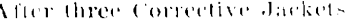

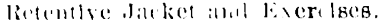




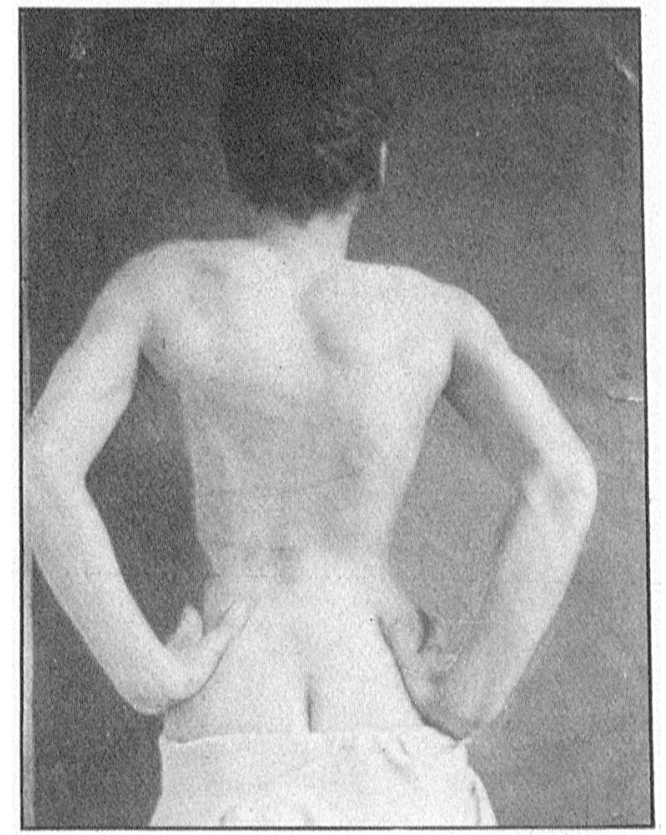

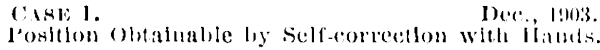

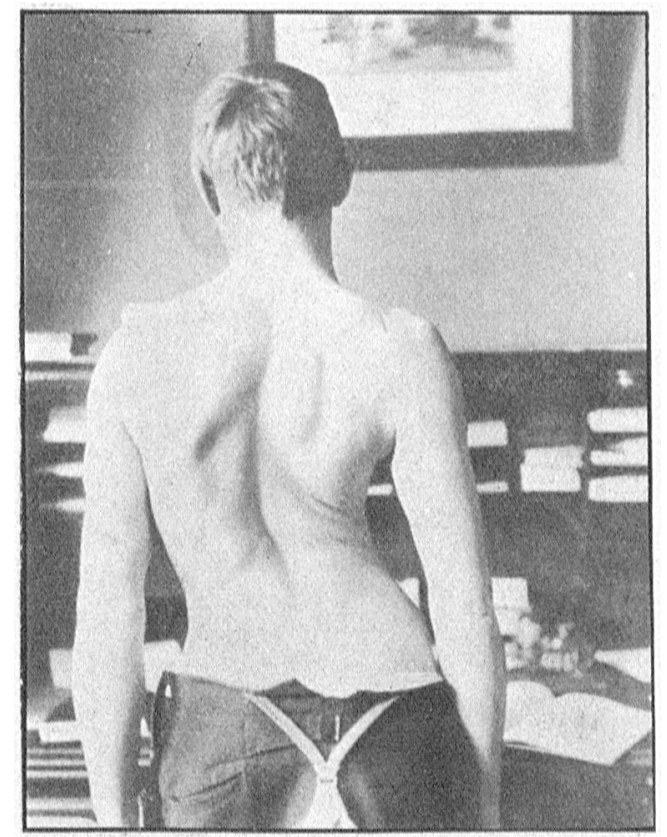

(ASEII.

l)e(e, I!n)!

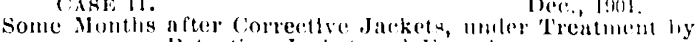
latentive Jacket and Eiendi-c.

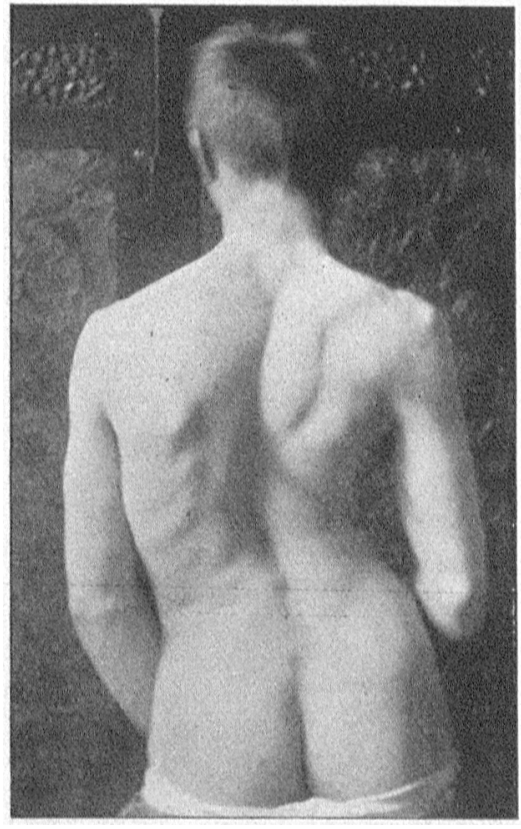

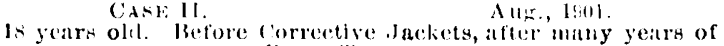

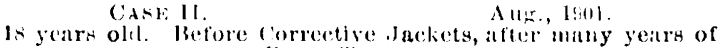
brate 'Trestument.

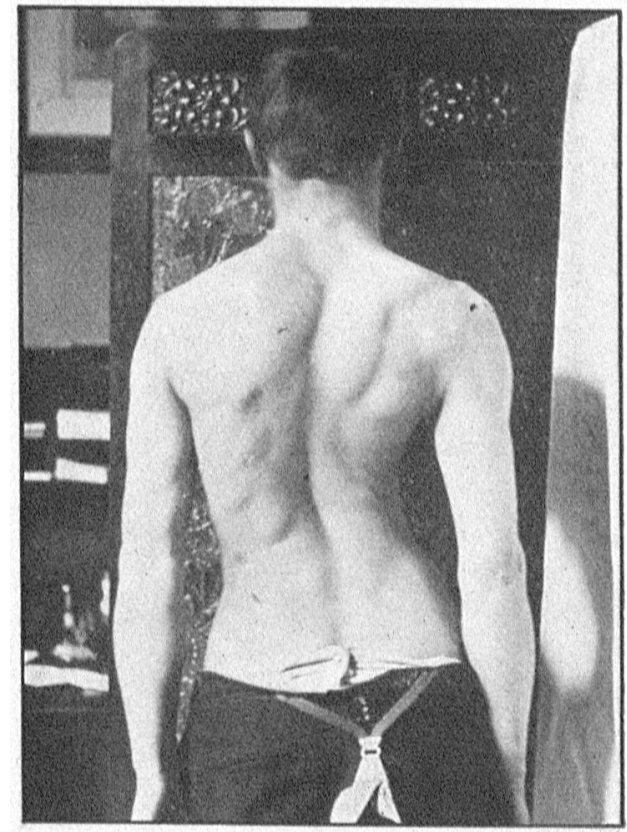

CA:E II. 


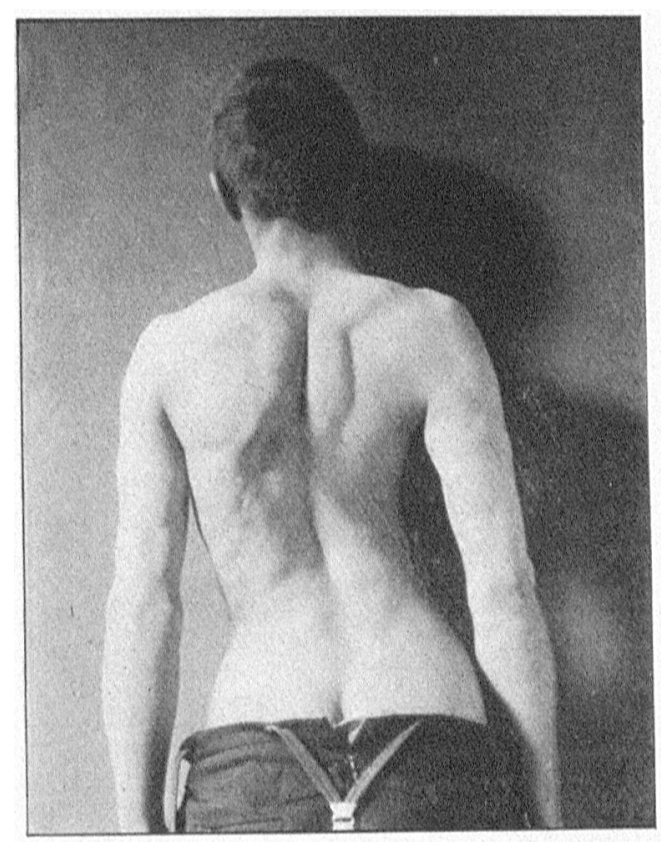

CANE II.

Niv., 1!n:3.

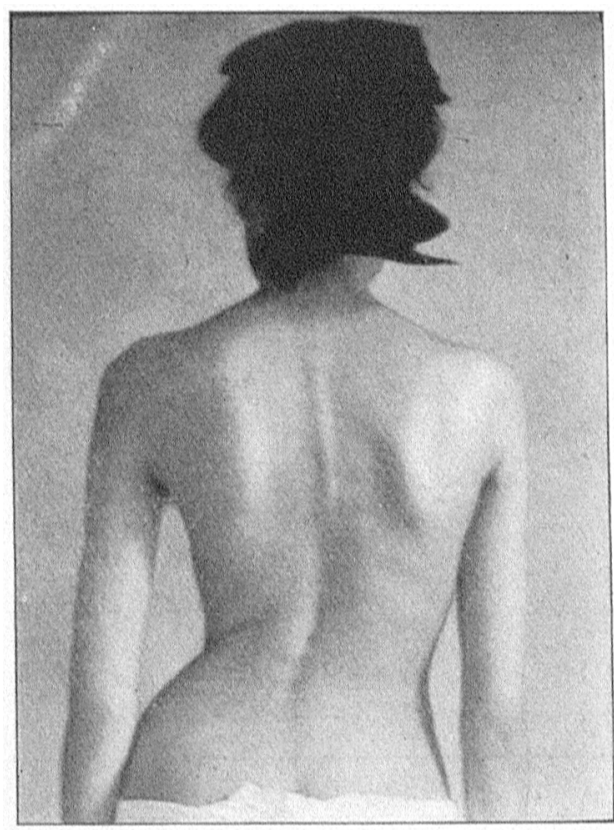

(ist: 111

July $\div, 1903$. is youry ald. Before any warment.

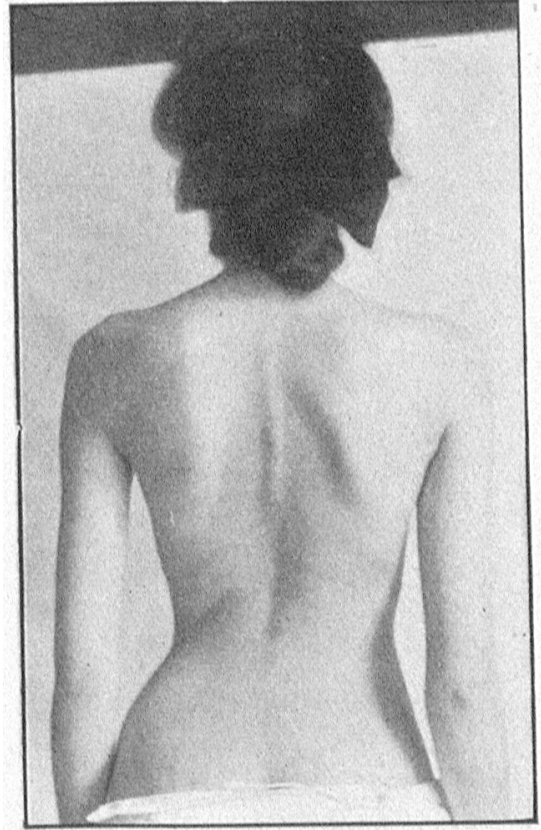

C.ISI: 111

Aler one dacket.

July 14,19103

(1) 11,1013

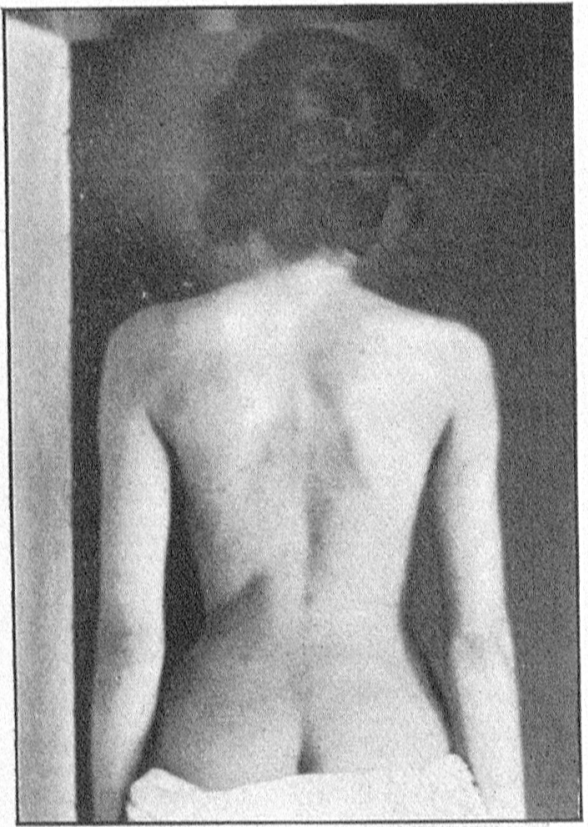

(AN 111 (). $1: 1, \cdots$

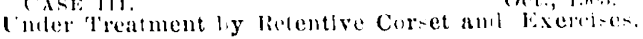



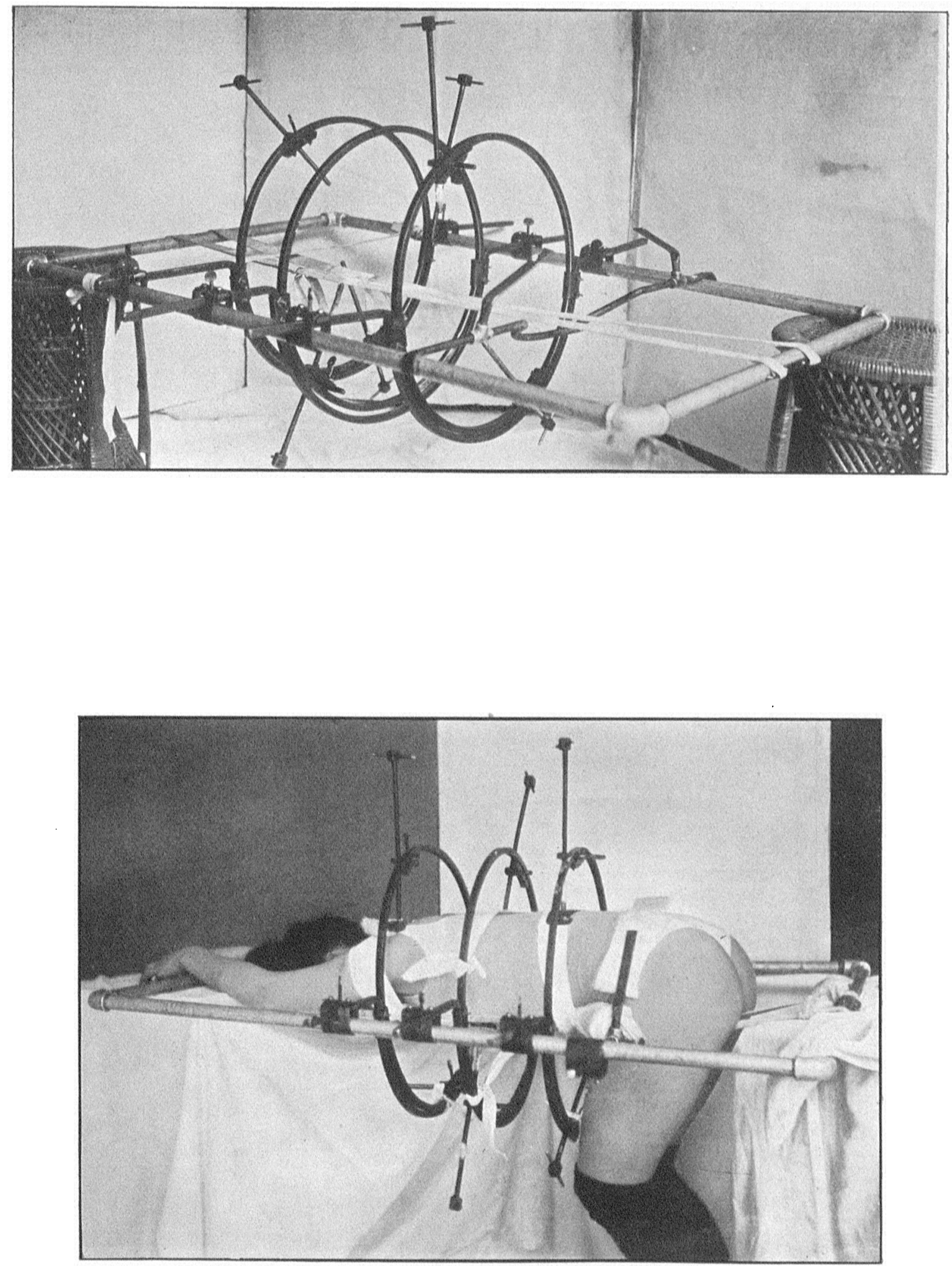

The Boston Medical and Surgical Journal as published by 
As to how such force can best be used two mechanical conditions bear upon the application of force to the deformed and curved spine.

The least economical use of force in straightening, for example, a bent stick is to pull the two ends away from each other, i.e., to straighten it by a pull in its length. 'The most economical use of force to straighten it is to take it by the two ends and press the point of greatest convexity against some resisting point, which shall push it straight. The relative force exerted will be recognized if one is reminded how easy it is to break a bent stick by striking it on the knee while one hand holds each end and how very diffieult it would be to break the same stick by a pull in its length.

Again if one wishes to secure the greatest side displacement in a flexible rod, such displacement. is more easily secured when the rod is not sliretched in its length. If a rubber tube, for ex- inple, is fastened to a table by two pins, one at

.h end, and is not put on the streteh the middle

it can easily be pulled an inch to one side by

- forefinger. If, however, it is pinued to the

le by two pins separated cnough to hold it on the stretch it will require much more force to displace it one inch to the side. The same is true of a strip of sponge rubber or a picce of ratitan.

To be sure that this theoretieal eonsideration applied to the human spine the following experiment was made at the Harvard Medical School by the courtesy of Prof. Thomas Dwight.

A young male carlaver was laid on the face and straps passed around the body at the level of the right shoulder and the right hip. These straps were then fastened to the left side of the table holding the shoulder and hip against pressure from the left. A strap was then passed around the left side of the thorax and by means of a spring balance pulled to the right. The side deviation of the spine was then measured at four levels, the measurements being taken from a base line connecting the cervical spine and the sacrum. The measurements were all made from pins driven into the spinous processes. Three experiments were made with a side pull of 25 lbs. and the results were recorded.

A Sayre head sling was then put around the head of the cadaver still lying on the face and a traction force of $75 \mathrm{lbs}$. was made, the feet of the cadaver being fastened to the table. While the traction on the head was thus in force the same side pull of $25 \mathrm{lbs}$. was made as before and the results noted. Two experiments of this sort were made. It was found that the spine without traction was displaced to the side nearly twice as far by a definite side pull as by the some amount of side pull when traction was being made.

A confirmatory experiment was made on a boy of fifteen, using $75 \mathrm{lbs}$. of head traction and $15 \mathrm{lbs}$. of side pull. The result was the same.

The conclusion is that extension of the spine by an upward pull on the head is a corrective force in scoliosis but that much more force is required to accomplish a certain amount of side correction than is the case if the force is applied from the side.

The other conclusion is that to secure the maximum of side displacement from a given amount of side pressure the spine must be slack and not; stretched in its length.

Finally, it may be said that to obtain growth in a desirable position, overcorrection of the existing deformity should be obtained where possible. It is obvious that to obtain this the use of great foree will be necessary.

The treatment of severe scoliosis by plaster jackets applied in a corrected position is not new. But the force used has been on the whole mild and generally applied to the spine during suspension. Bradford and Brackett ${ }^{18}$ described a frame in which the jacket was applied as the patient lay prone, but even here head traction was used. Hebel, Calot, Redard and others have also used the horizontal position. ${ }^{10}$ Yet in 1898 Hoffa, the well-known German authority, wrote in his textbook, "Bei den Skoliosen dritten Stadiums lasst sich eine Besserung in der Contour des Rumpfes erzwingen, man kann cin weiteres Fortschreiten der Verkrummung bis zum Aeusscrsten verlusten und die Interkostal Neuralgien beseitigen." 20

The whole question was given a new impelus by Calot's work on the forcible correction of the deformity in Pott's disease published in 1896, and a few articles dealing with the subject have appeared since then. ${ }^{21}$ The later tendency has been toward the use of much greater force than was previously employed.

The most noteworthy advance in the forcibls corrective treatment of seoliosis has been mair by Wullstein, who has applied the above-men tioned principles with force and precision ald, who publishes photographs showing mark oo improvement in patients. His method is $t$. forcibly extend the head while the patient's pelvis is strapped to a seat which can be tilied to make the pelvis oblique and which also can be rotated to change the relation of the pelvis to the spine. Lateral pressure is made by pads rumning in horizontally from the sides of the apparatus. By a combined motion of the seat and adjustable pads any degree of twist of the spine upon the pelvis may be produced. Wullstein uses an appalling amount of force in his traction, applying up to $250 \mathrm{lbs}$. of pull, and he applies a plaster jacket while the patient is thus stretched and pushed into a corrected position. This jacket embraces, as must all such jackets to be wholly efficient, the chest, shoulders and head.

I do not personally believe that Wullstein's attempt to correct rotation by a torsion of the whole spine is based upon correct principles nor that torsion can be so corrected (for reasons given in another paper), ${ }^{22}$ but with this unimportant exception the method is progressive, rational and effective.

The amount of force required, however, is excessive, as must be the case where force is not 
economically applied. He is attempting to position I have endeavored to retain it by porstraighten the bent stick by pulling the two ends tative apparatus and gymnastic exercises.

apart, and when a great amount of force has No preliminary treatment in the way of thus been expended in stretching the spine, stretching and forcibly manipulating the spine lateral pressure is applied, when it also must be has been used in preparing patients for the al)pushed to an extreme on account of the stretch- plication of the jacket. Both Wullstein and ing of the spine in its length.

I had been working at the same problem in the attempt to utilize the forec in its most efficient way by making side pressure, that is, attempting to straighten the bent stick by bending it over something instead of trying to pull apart its ends, and published my first results in $1901 . .^{23}$

More extended experience has confirmed me in the belief that even in adults much correction may be accomplished by the use of properly directed side force and that, at least in growing persons, retention in the corrected position causes diminution of the bony deformity.

The criticism that such correction is not likely to be permanent at once presents itself. The method in its later application is too new to enable one to make the statement that such results have proved to be permanent in cases observed, consequently one must consider the probabilities on general grounds. The grounds that lead one to suppose that retention of the corrected spine in a corrected position over a sufficient period will lead to a change in the shape of the bones of the vertebral column and to a permanently improved position are as follows:

(1) Clubfoot may be cured by a similar procecding.

(2) The bones of the feet of Chinese women rank are seriously misshapen by retention in unnatural position. ${ }^{24}$

3) Wullstcin produced bony changes in dogs

a few months of abnormal position.

(4) W. Arbuthnot Lane has demonstrated hat the carrying of heavy loads by laborers will produce changes in the bony skeleton and that the changes vary according to the habitual position of the load, ${ }^{25}$ the bones subject to the grcatest pressure undergoing changes in shape.

(5) The fact that bone under pressure changes shape after growth has been reached is shown in the fact that scar tissue pressing on bone will cause a change in shape, ${ }^{20} e . g$. , on the chin.

(6) Pressure of tumors or ancurism will cause absorption of bone.

These facts all point to the eonclusion that bone alters its shape under changed conditions of pressure, and that although this would be more marked during growth, the phenomenon is not unknown in adult life.

For a permanent cure, therefore, retention for some time in the corrected position is essential.

My attempt, therefore, has been to exercise as much side pressure as can be borne upon the slack spine (that is, the spine not stretched in its length). I have done this in the hope of stretching muscles and ligaments and thus in time changing the relation of vertebræ misshapen by was worked out mechanically by 1)r. Z. 13. 
assistant in the lateral curvature clinic at the Children's Hospital.

The apparatus constructed by him consisted of a heavy gas-pipe frame three by four fect. The patient lies face downward on two welobing strips running from end to end of the frame with the legs flexed. Near the bottom of the frame is an adjustable erossbar bent to fit into the flexure between the thigh and the pelvis on which the patient rests the lower part of the body. Sliding on this bar are two arms, which slide in and clamp down on the buttocks, holding the pelvis steady on the crossbar. This bar is movable from side to side in order to induce or correct curvature in the lumbar region when necessary. There are three vertical transverse rings two feet in diameter fastened to pieces on the sides of the frame so that they can be moved to any desired point along the frame. 'These rings are also movable from side to side and by an independent. movement they ean also be rotated through a half circle. Any one of these movements can be checked at any point by turning a serew. The shoulders are held by a pair of axillary straps fastened together by a strap across the chest in front. These straps are suspended from the ring nearest to the top of the frame and can be made to hold the shoulders in any desired degree of twist by a rotation of the ring.

Each ring is provided with two long screws at the two poles of the ring. These screws are adjustable upon the ring and can be set at any desired angle to it. liy rotating the ring and adjusting the angle of the screws they can be marle to screw down or up upon any part of the back or chest.

For the application of the jacket the patient lies on the face on the two webbing strips, the lower part of the trunk resting on the cross rod and the bars clamping the buttocks; the feet rest on the floor and the arms are extended above the head. The rings are then adjusted at the two levels where it is desired to make correction, generally in the dorso-lumbar and the dorsal regions. For side correction a bandage is fastened to one side of the ring, carried around the patient's side over a heavy pad of felt and back to the ring. The same is done to the other ring at the other level where side correction is desired, while the top ring controls the shoulders. The rings are then pulled to one side, the bandages around the patient tighten and any cndurable degree of side correction olstained.

When the side correction is made the ring is rotated till the screws are opposite the points where it is desired to correct rotation. They are then serewed down on to the patient, their points being protected by sheet-iron pads two by three inches, which are covered with heavy felt. These pads are incorporated in the jacket.

The shoulders are controlled by the axillary pads attached to the upper ring along with screw pressure up or down as desired. In the correction each level is separately attacked.

The pelvis is always held firmly and cannot rotate. If two curves exist, correction of the lower curve is first made - first, side correction. then rotation correction. Next, the dorsal curve is attacked and corrected to square with the pelvis. The shoulders are finally inspected, pulled to one side if necessary and twisted into a parallel position to the pelvis. A plaster jacket is applied to the patient, held in this way. It is easy to see that the method is perfectly definite and that the amount of foree at the operator's disposal is very great.

Separate correction in two planes may be made at any level while the pelvis is firmly held and eorrection at one place may be made independently of eorrection at any other place and either side deviation or rotation or both may be corrected at each level.

In the third ease in which the apparatus was used a child six years old with a very severe curve from infantile paralysis was corrected. The deformity yielded readily without much pain and almost wholly disappeared; a jacket was applied; ether was not used. The eliild showed signs of collapse in the night, and the next morning was somewhat cyanotic and stupid although conscious, radial pulse was absent, the extremities were cold and bluish and the condition generally alarming. The jacket was split and the alarming signs disappeared.

In the eases in which this frame has been used it has secmed to have very great corrective power, and great power is needed if overeorrection is to be obtained, which, just as in clubfoot is the desideratum.

Such corrective jackets are worn for a period of two or three weeks and changed once or twice, just so long as further eorrection secms obtainable by another jacket. In the earlier jackets good eorrection seemed to have heen obtained in a week and that period was adopted, but that time seems on general grounds to be too short and the longer period has been substituted. The last corrective jacket when removed is used as a mold for a plaster torso and a leather or celluloid or other retentive corset constructed from it. This is worn day and night and only removed once a day for heavy corrective gymnastic work, which is pushed to the limit of the patient's capacity.

Such retentive apparatus, whatever it is, should aim at holding the patient in an overcorrected position or as near it as possible from the pelvis to the base of the skull.

It is not intended here to dwell on braces or corsets, but rather on the essentials of the method. A useful brace, however, for outpatient work is found in a leather corset stiffened by bayberry tallow with a window for pressure from a leather pad on the convexity, the point of counterpressure being offered by an iron bar and two pads, one over the pelvis and one in the axilla, on the other side of the jacket. It is essential that room be given on the side away from the pressure for the patient to be pulled over and this is arranged by cutting out part of the side of the jacket on the side of the concavity of the curve and pulling by straps on the 
pad set in the window over the convexity. In my experience jackets may be gradually discontinued in all but the extreme paralytic cases after a period of perhaps two years.

With regard to the relative merits of the suspended and the prone position it may be said -

That suspension works on the whole spine and distributes itself and untwists the rotation while it straightens the lateral curve, but it is obviously not corrective enough by itself when pushed to its limit or Wullstein would not have to add to it side pressure. The ehief objection to it is that it is an uneconomical application of corrective force and that pushed to the point of obtaining overcorrection it must reach an almost unendurable grade of pull.

In the prone position fainting is less likely, there is less discomfort, and far less force is required to obtain a definite amount of correction, because the force is more economically applied and the back can be inspected through the early part of the process.

Personally, I think it a great advantage to have the lumbar curve held by the jacket as flat as possible, as thereby I believe that a corrective extending force is exerted upon the dorsal curve. ${ }^{28}$

The claims of efficiency to be made for the apparatus may be repeated:

(1) The most economical use possible is made of the corrective force by applying it sideways and thus less force is required or the same amount of force will do more than in extension of the spine.

(2) The force is applied to the spine while slack and not made tense by extension.

(3) Side correction is made by one part of the appliance.

(4) Correction of rotation is made by another part of the appliance.

(5) The pelvis is held in a position which ensures some flattening of the lumbar curve, which in the upright position tends on account of the balance of the patient to bring about straightening of the dorsal curve.

(6) Finally, it may be said that general pathological considerations would seem to indicate that retention in the corrected position should induce changes in the shape and relations of the misshapen bones.

Casz I. Boy, thirteen years old in 1900. Severe infantile paralysis of one side of back and one leg, shortening of one leg of one and a half inches. Treatment for some years by braces and gymnastics. Forcible correction by four jackets in January, 1903. Since then retention in celluloid jacket, daily stretching in the prone position and hanging, with a few gymnastic exercises to develop the remaining muscles. A doctor who had given exercises in 1901 and previously and who examined the boy in Decomber, 1903 , wrote, "I found that he had gained considerably in muscular power. The back muscles were much stronger and the abdominal muscles had gained also."

CASE II. Eighteen years old in 1901. Severe infantile paralysis of one side of back and of leg; very rigid. Brace treatment for many years. Plaster correction jackets applied in 1901. Retention jacket and exercises since then. Gain in height since 1901, seven-eighths of an inch.

CASE III. Girl, eighteen years old, no previous treatment. Rigid scoliosis; no paralysis; four corrective jackets in July, 1903; since then exercises and retention corset.

\section{RHELRWNCHS.}

2 Trans. Am. Orth. Ase'n, vol. ix, p. 10 and pp. 23-32.

3 Teschnor: N. Y. Med. Rec., Dec. 6, 1903

'Mirich: N. Y. Mod. Journ . Oct. 7, 1808.

5 Hoffa: Orthopädische Chirurgie, last od.

"Weigel: Trans. Am. Orth. Ass'n, vol. v, 5, p. 265.

7 Wullstein: Dio Skoliose, otc., Zeitschr. f. orth. Chir., vol. x, 2, p.

177.

Schodle: Doutscho med. Wcheft... vol. xviii, 249, 1892

I Juning \& Schulthess: Orthop). Chirurgie, Munich, p. 285, 1001. 10 )ologa: Path. \& Ther. der kincl. Skoliose. Leipzig, 1807, p. 117. Juning \& Schulthess: Orth. Chir $1001, n^{2} 310$. Redard: Chirurgie orthopediquo, 1802, p. 382. Hoffa: Orthopindieche Chirurgio, last od. Bradford \& Lovett: Orthopedic Surgery, $2 \mathrm{~d}$ ed., 1800, p. 138. Wullstein "Ooitsehr. f. orth. Chir., $x, 2,328$.

11 Hoffa: Zeitschr. f. orth. Chir. 1806, p. 401.

12 Shafier: Am. Med. Surk. Buli., Jan. 1, 1804

13 Journ. of Orth. Surkery, vol. i, No.' 2 .

1" Hoffa: Orth. Chir., 3d od., p. 346. Freiberg: Cincinnati LancetClinic, Fob. 16, 1901. Shauds: Virginia Med. Somi-Monthly, April 8, 1808. A. M. Phelph: N. Y. Post-Graduate, Octobor, 1901. $\Lambda$. B. Judron: N. Y. Med. Journ. 1003.

15 Wullstein: I,oc. eit.

16 Lorenz quoted by Whitman: Orth. Surgery, N. Y., 1901.p. 585. 17 F. H. Bralford: Bost. Med. \& Surg. Journ, 1881, p. 241.

18 Bost. Med. \& Surg. Journ., Oet. 10, 1003. Bost. Mod. \& Surg. Journ., Mny 11, 1803.

10 Reclard:'Trans. Am. Orth. Ass'n, vol. xi, p. 447.

20 Hoffa: Lehrbuch der orth. Chir., 3 te Auflage.

21 Schauz: Berl. kl. Wehsft., $1902,48$.

22 The Eloment of Torsion in I ateral Curvature, Bost. Mod. \& Surg. Journ., Aug. 6,1003 . \$ The Mechanies. of lateral Curvature, otc., Bost. Med. \&
Surk. Journ. Oet. 31, 1001.

24 Brown: Journ. Med. liesenrch, Docember, 1903

25 Guy's llosp. lioporta, vol. xxviii.

2n Zeigler: P'ath. Jinglish od., 1896, vol. ii, p. 146

27 Hussy: Vohor dio Wirk der orthi. Corsets bei Skol., etc., Ztwchr. f. orth. Chir. vol. viii, 202: Schulthese: Cent. f. Chir., 1890 .

${ }_{23}$ Lovett: The Mechanics of lateral Curvature, otc. Bost. Med.

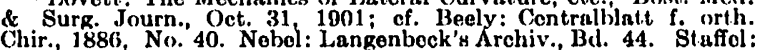
Cent. f. orth. Chir., 1885 .

\section{HYDROTHERAPEUTIC PRESCRIPTIONS.}

DY JOskir H. PIATT, A.M., M.D., Boston.

Physician to Out-Patients, Massachusetts General IIospital; Assistant in Theory and Practice of Physic, Harvard University.

DURING the past decade rational hydrotherapy has made great advances, particularly in Germany and Austria. The position hydrotherapy occupies to-day in the treatment of disease is largely due to the physiological and clinical investigations of Winternitz of Vienna, which placed the empirical water treatments on a scientific foundation. We are now able to predict, as von Hoesslin ${ }^{1}$ says, the action of a definite hydrotherapentic procedure in a given case with as much certainty as we can that of morphine and digitalis.

1)r. S. Solis Cohen, in his "System of Physiologic Therapeutics," suggests that "there should be maintained in every city an establishment to which any physician might refer his paticnts with a definite hydriatic prescription, just as he can now send them to the apothesary with a definite pharmaccutic prescription." A number of Boston physicians, feeling the neel of such an establishment, met together at the suggestion of Dr. J. J. Putnam on Oct. 13, 1903, to consider the advisability of maintaining an institution for physical therapeutics "where pri1 v. Hoesslin. Penzoldt u. Stintzing Handbuch der 'l'herapie innorer Krankheiton, Jena, 1003, v, p. 110. 